\title{
Applications of vertical steel pipe dampers for seismic response reduction of steel moment frames
}

\author{
Junaedi Utomo $^{1 *}$, Muslinang Moestopo ${ }^{2}$, Adang Surahman ${ }^{2}$, and Dyah Kusumastuti ${ }^{2}$ \\ ${ }^{1}$ Civil Engineering Department, Universitas Atma Jaya Yogyakarta, Yogyakarta, Indonesia. \\ ${ }^{2}$ Faculty of Civil and Environmental Engineering, Bandung Institute of Technology, Bandung, \\ Indonesia.
}

\begin{abstract}
A newly developed vertical steel pipe damper is introduced to improve the seismic performance of steel moment frames. The damper exhibits large lateral stiffness and excellent capability to dissipate energy due to earthquakes. It provides a reliable, compact, inexpensive, and replaceable damper. Improved performance of the structure is verified analitically using a four-story steel moment frame equipped with steel pipe dampers. Vertical steel pipe dampers are placed between any two points where large relative motion exists during earthquake excitation. A nonlinear dynamic analysis of the structure using PERFORM-3D software demonstrated the significant benefit of equipping the structure with steel pipe dampers. All structural components, except the steel pipe dampers, remain elastic during earthquake excitation. Structures properly designed with vertical steel pipe dampers will only require minimum postearthquake inspection and limited damage. Some practical issues associated with the application of vertical steel pipe dampers to building structure for seismic response reduction are presented in this paper.
\end{abstract}

\section{Introduction}

A newly developed vertical steel pipe damper has been introduced to improve the seismic performance of steel moment frames [1]. The damper has large lateral stiffness, small yield displacement and excellent capability to dissipate a tremendous amount energy. The damper is intended to be installed in low to medium rise structures. An improved performance of a four-story steel moment frame with and without steel pipe dampers was verified analytically using north-south components of the El-Centro 1940, Chi-Chi 1999, Fukushima-Hamadori 2011 and Padang 2009 earthquakes accelerograms. The structure was not intended to be designed for a specific site. Therefore no spectral matching, to obtain design ground motion time histories to match a target response spectra of a site, was done. The results of the nonlinear dynamic analysis of the structure demonstrated the significant benefit of equipping the structure with vertical steel pipe dampers. All structural components, except the dampers, remain elastic during four strong earthquake excitations.

\footnotetext{
* Corresponding author: utomoj@live.com
} 


\section{Vertical steel pipe damper}

Steel pipes in vertical position are sensitive to the diameter $(D)$ to thickness ratio $(t)$ of the pipes. The schedule 80 carbon steel pipe which has small $D / t$ ratio was chosen to avoid buckling in middle part of the pipe. Pipe having $D=114.3 \mathrm{~mm}, t=8.6 \mathrm{~mm}$ and height $(h)=$ $200 \mathrm{~mm}$ was used as the material of the damper. Abebe et al. [2] proposed the ratio of height to diameter of the pipe as $\sqrt{ } 3$ so that bending and shear stress yield simultaneously. The results of simple tensile tests to obtain the material properties of the steel pipe and plate are shown in Table 1. Figure 1 shows the results of numerical simulation using ABAQUS [3] for bare pipe fixed at both ends subjected cycles of increased amplitude of lateral displacement by $1 \mathrm{x} \delta_{y}$ in each consecutive cycle ( $\delta_{y}$ is the yield displacement of the damper). As shown in Figure 1, no local buckling occurred at the middle part of the pipe but local buckling occurred at the ends of the pipe manifesting in unstable hysteretic curve. The specimen of the bare pipe had been tested using the same cyclic loading above, and fracture occurred at the heat affected zone area (HAZ) close to the ends of the pipe. Some kind of strengthening to the bare pipe are required to avoid buckling at ends of the pipe, to relieve the stresses at the ends of the pipe, and to relocate the fracture away from HAZ area.

Figure 2 shows the two improved model of vertical steel pipe dampers. The model of vertical steel pipe dampers shown in Figure 2a had been tested, and fracture occurred at the heat affected zone area (HAZ) close to the ends of the pipe. The details of the strengthening plate outside the pipe were improved so that: (1) buckling at the pipe was eliminated; (2) connection failure at the ends of the pipe was avoided; (3) fractures at HAZ region were avoided; (4) early fractures at points of high intense stress were postponed, and (5) extensive yielding was concentrated in the middle part of the pipe. As shown in Figure $2 b$, curved and tapered strengthening plate were used to prevent buckling at the ends of the pipe, to concentrate the extensive yielding in the middle part of the pipe and to postpone and to shift fracture locations away from HAZ areas.

Table 1. Material properties of the steel used for numerical simulation

\begin{tabular}{|l|c|c|c|c|}
\hline Steel & $\begin{array}{c}\text { Modulus of elasticity } \\
\text { (MPa) }\end{array}$ & $\begin{array}{c}\text { Yield stress } \\
\text { (MPa) }\end{array}$ & $\begin{array}{c}\text { Ultimate stress } \\
\text { (MPa) }\end{array}$ & $\begin{array}{c}\text { Breaking strain } \\
\text { (\%) }\end{array}$ \\
\hline Pipe & 200.000 & 330 & 465 & 37 \\
\hline Plate & 200.000 & 360 & 500 & 25 \\
\hline
\end{tabular}

\section{Restoring Force vs. Lateral Displacement}

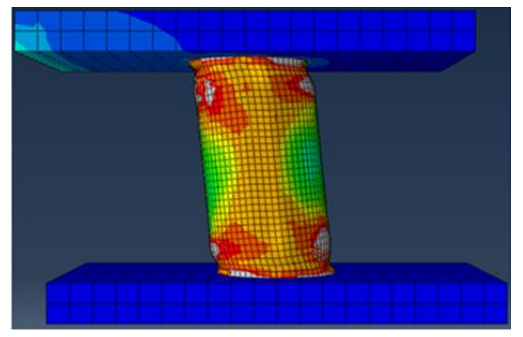

(a)

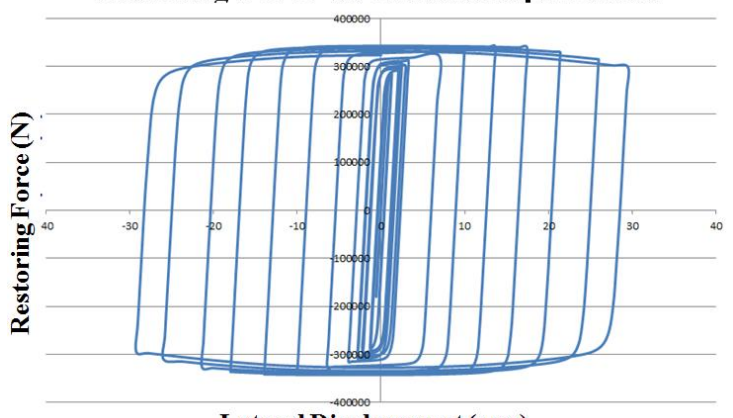

Lateral Displacement (mm)

(b)

Fig. 1. Local buckling at the ends of the bare pipe: (a) von Mises stress distribution and (b) Hysteretic curve 


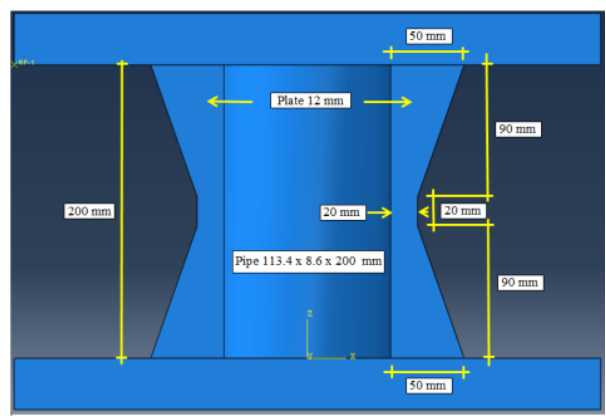

(a)

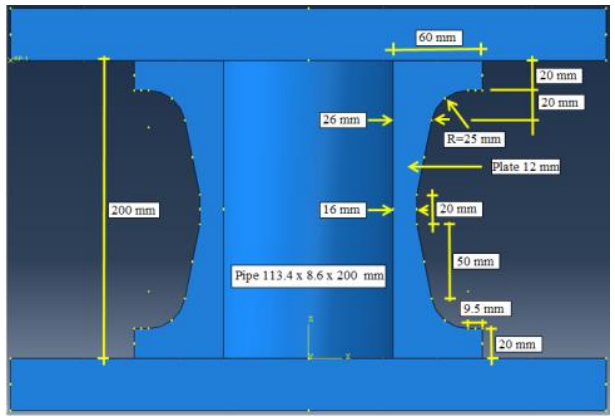

(b)

Fig. 2. Details of the improved model of vertical steel pipe dampers: (a) Strengthened with a pair of trapezoidal shape plates and (b) Strengthened with a pair of curve shape plates

Figure 3 shows the von Mises stress distribution of the improved model shown in Figure $2 \mathrm{~b}$. The results of the numerical simulation show: (1) The point of high intense stresses where fractures are expected to happened has been shifted away from HAZ region near the ends of the pipe; (2) Welded connections are placed at low stress areas, and (3) The high stresses at the ends of the pipe are relieved. The improved model of the vertical steel pipe damper has been tested using ATC-24 loading protocol using cycles of increased amplitude of lateral displacement by $1 \mathrm{x} \delta_{y}$ in each of three consecutive cycles.

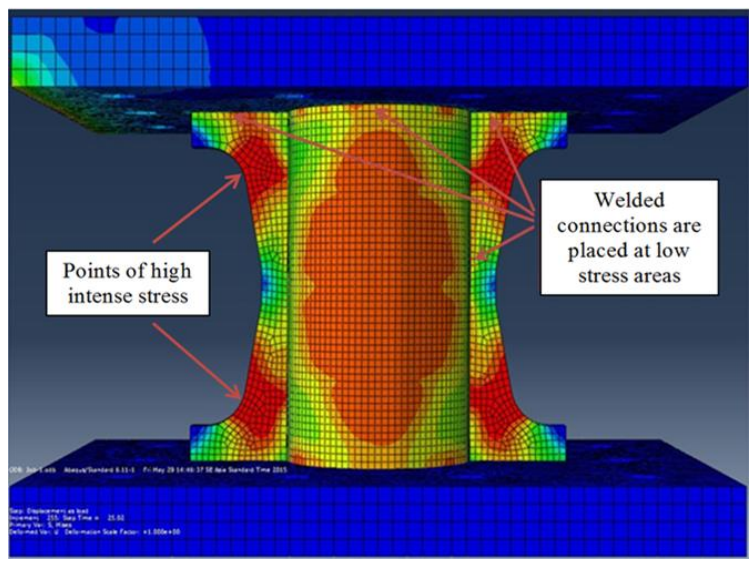

Fig. 3. von Mises stress distribution of the improved model of the vertical steel pipe damper

The stable parts of the hysteretic curves of the test results of the dampers were plotted in Figure 4. Figure $4 \mathrm{a}$ shows the plot of two graphs of the bare pipe damper and the vertical pipe dampers strengthened with a pair of trapezoidal shape plates on one Cartesian coordinate system, and Figure $4 \mathrm{~b}$ shows the same plot of the bare pipe damper and the vertical pipe dampers strengthened with a pair of curve shape plates. The number and distribution of plastic cycles from the test results determined the energy dissipation capacity of the dampers. Table 2 shows the number of plastic cycles and the energy dissipated by each of damper due to the following cyclic displacement loadings: (1) For the bare pipe and the pipe strengthened with a pair of trapezoidal shape plates, the displacement loading amplitude was increased in each consecutive cycle by $1 \times \delta_{y}$, and (2) For the pipe strengthened with a pair of curve shape plates, the displacement amplitude was increased in each three consecutive cycles by $1 \mathrm{x} \delta_{y}$ (ATC-24). The number of plastic cycles from the test results reflects the quality of the detailing of the dampers. As shown in the last row of Table 
2, applying smooth geometry configuration to the strengthening plate outside the pipe manifested in the increase capacity of the energy dissipation of the damper significantly.

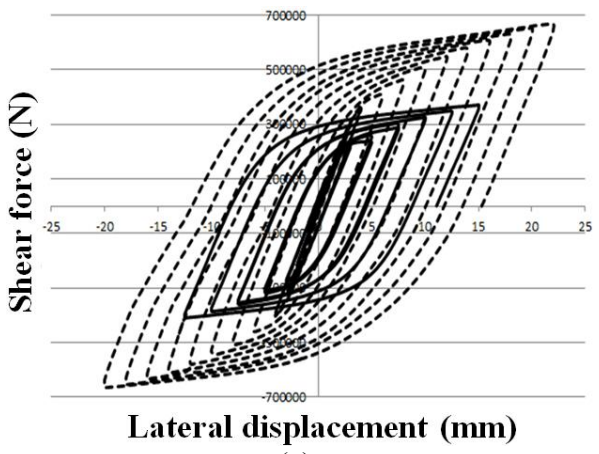

(a)

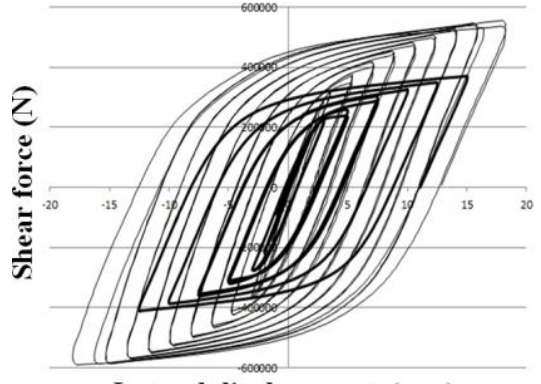

Lateral displacement $(\mathrm{mm})$

(b)

Fig. 4. Plot of two graphs of stable parts of hysteretic curves of vertical steel pipe dampers: (a) Bare pipe vs. pipe strengthened with a pair of trapezoidal shape plates, and (b) Bare pipe vs. pipe strengthened with a pair of curve shape plates

Table 2. Number of plastic cycles and increase capacity of energy dissipation

\begin{tabular}{|c|c|c|c|}
\hline $\begin{array}{c}\text { Vertical steel } \\
\text { pipe dampers }\end{array}$ & $\begin{array}{c}\text { Number of } \\
\text { Plastic Cycles }\end{array}$ & $\begin{array}{c}\text { Total Dissipated } \\
\text { strain energy } \\
\text { (N.mm) }\end{array}$ & $\begin{array}{c}\text { Increase capacity of } \\
\text { energy dissipation } \\
(\mathbf{\%})\end{array}$ \\
\hline & 7 & $0.325 \mathrm{e}+08$ & - \\
\hline & 8 & $1.09 \mathrm{e}+08$ & 236.72 \\
\hline & $\mathbf{2 9}$ & $\mathbf{2 . 4 5 e + 0 8}$ & $\mathbf{6 5 4 . 0 8}$ \\
\hline
\end{tabular}

\section{Application of vertical steel pipe dampers}

The vertical steel pipe damper strengthened with a pair curve and tapered plates will be installed in a four-story steel moment frame to reduce the seismic response of the building due to four strong earthquakes. Nonlinear dynamic procedure was used to access the performance capability of the building. Limiting the lateral defection of the damper to $10 \mathrm{x} \delta_{y}\left(\delta_{y}=1.80 \mathrm{~mm}\right.$ is the yield lateral displacement of the damper) due to four strong earthquakes was selected as one of the performance objective of the building. A preliminary designed has been carried out to estimate the required number of dampers in each story of the building. A computational model of the building that incorporates the nonlinear load-deformation characteristic of the individual damper was built using PERFORM-3D [4]. The computational model was then subjected to the north-south component of the Chi-Chi 1999, El-Centro 1940, Fukushima-Hamadori 2011, and Padang 2009 ground motion time-histories. The resulting maximum absolute deflection of the dampers was directly compared to the performance objective of the building. 


\subsection{Steel moment resisting frame}

A four-story steel moment resisting frame shown in Figure 5 was used to study the application of the vertical steel pipe damper. A number of end releases were applied so that the lateral load resisting systems in the building are the peripheral frames. One-way slab systems were applied to all floors. The secondary beams were not shown in Figure 5.

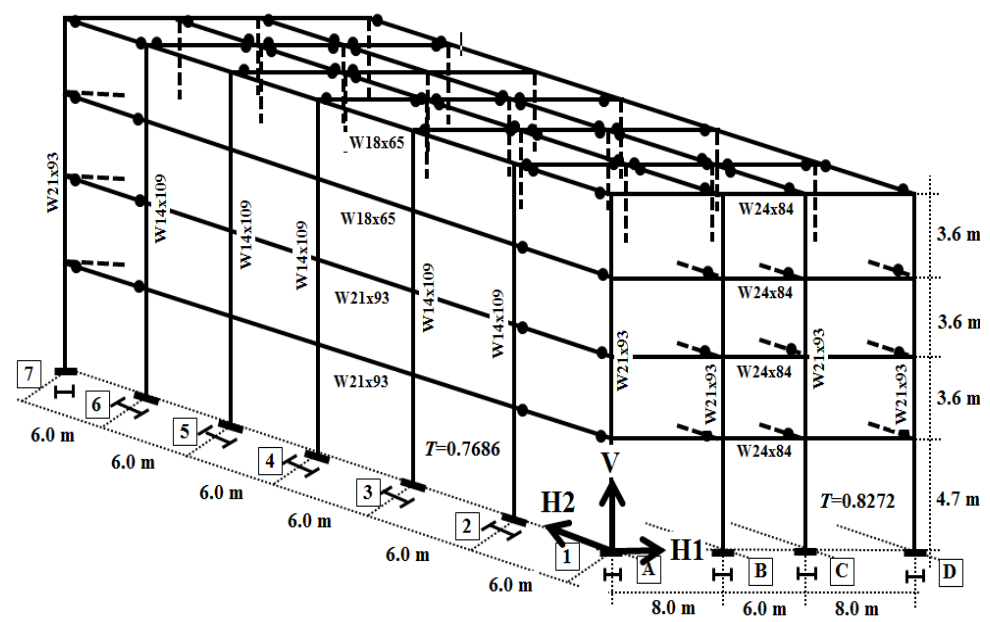

Fig. 5. Four-story steel moment resisting frame

The superimposed specified loads are as follows:

Gravity loading:

- Live load: Roof LL $=1.0 \mathrm{kPa}$, Floor $\mathrm{LL}=2.4 \mathrm{kPa}$

- Dead load: Floor weight plus topping $=3.6 \mathrm{kPa}$, Partitions $=1 \mathrm{kPa}$

Materials:

- Concrete: $24.0 \mathrm{MPa}$

- Reinforcing steel: ASTM A572 steel, grade $50 f_{y}=345 \mathrm{MPa}$

Elements dimension:

- Exterior columns: W21x93 (along H1), and W14x109 (along H2)

- Interior columns: W12x72 (along H2)

- Exterior beams: W24x84 (along H1), W21x93 and W18x95 (along H2)

- Interior beams: W24x84 (along H1), W21x93 and W18x95 (along H2)

Fundamental periods:

$-T=0.8272$ seconds (along H1)

$-T=0.7689$ seconds (along H2)

\subsection{Modelling dampers as inelastic components}

Originally all the columns height were $3.6 \mathrm{~m}$ and the four-story steel moment frames had been designed to withstand moderate intensity earthquake. The height of the first floor column was modified to $4.7 \mathrm{~m}$ and the doubler plate at panel zones were eliminated to purposely create problems into the four-story steel moment frames. These problems will be eliminated by installing dampers in the peripheral frames of the buildings. 
Test results data of the vertical steel pipe damper were used to model shear vs. lateral displacement of the damper. Seismic isolator component in PERFORM-3D [4] was used to model the damper as shown in Figure 6.

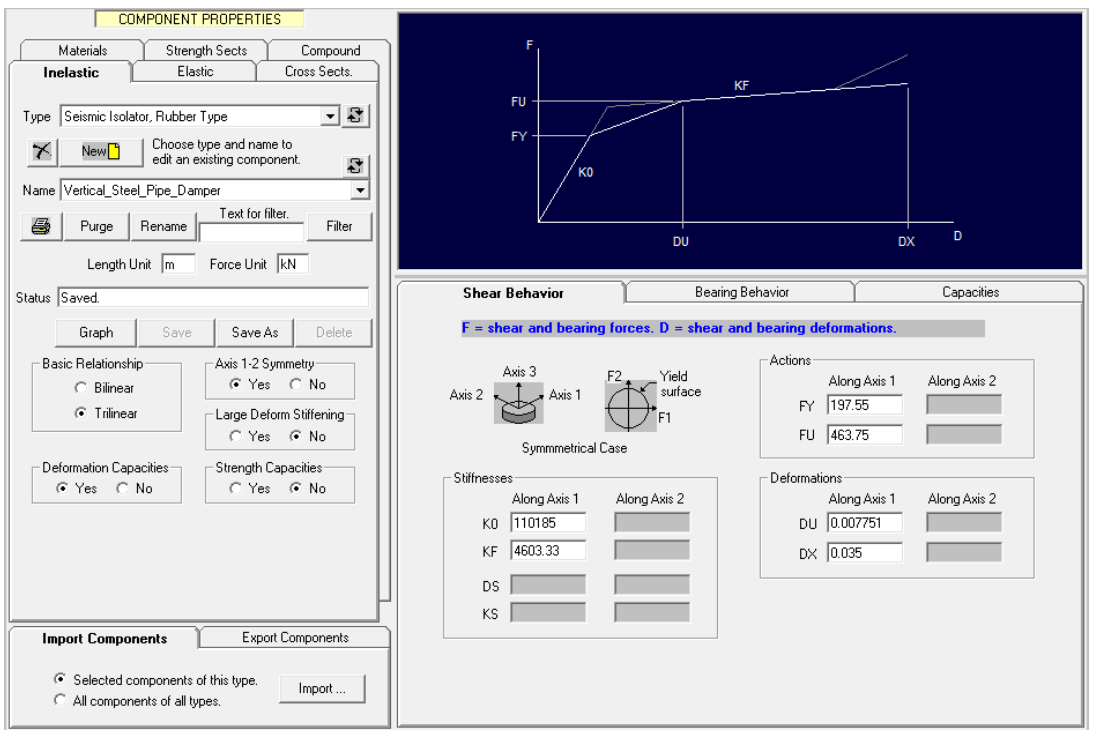

Fig. 6. Trilinear model of the force vs. displacement of the vertical pipe damper

The performance objectives of the steel frames equipped with dampers are:

1. Energy dissipation is concentrated in dampers meaning other components of the steel frames, except the dampers, remain elastic.

2. Inter-story drifts reduction at all levels are significant

3. Absolute lateral deflection of the dampers is less than $10 \mathrm{x} \delta_{y}$.

\subsection{Estimating the number of dampers in each story}

The required number of dampers in each story had been estimated using energy-based method proposed by Benavent-Climent [5]. The required lateral stiffness and lateral strength of the damper for near-fault ground motion were determined from input energy spectra for moderate-seismicity regions proposed by Benavent-Climent et al. [6]. The configuration of the dampers in the peripheral frames along $\mathrm{H} 1$ and $\mathrm{H} 2$ are shown in Figure 7. Auxiliary structures in the form of triangular bracings are needed to install dampers between two points where large relative motion exists during earthquake. Auxiliary structures shown in Figure 7 were chosen to minimize the influence of axial forces to the dampers.

A computational model of the four-story frames, that incorporate the nonlinear loaddeformation characteristic of the individual damper shown in Figure 6, was built using PERFORM-3D [4]. For assessment of the performance of the building equipped with dampers, the computational model was then subjected to the north-south component of the four strong earthquakes time histories, and the results were evaluated. 


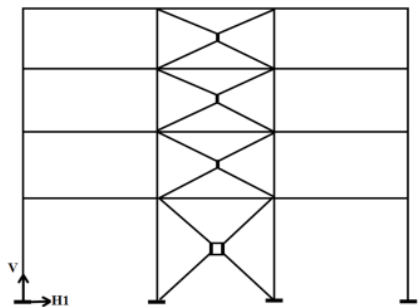

(a)

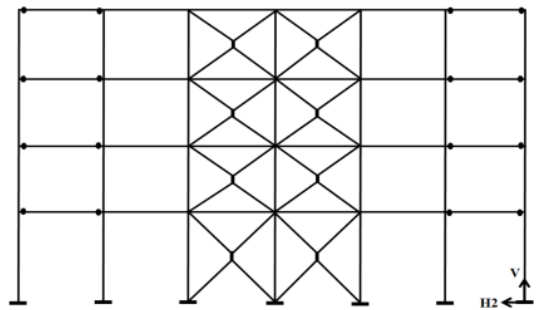

(b)

Fig. 7. Configuration of the dampers in peripheral frames: (a) Two peripheral frames along H1, and (b) Two peripheral frames along $\mathrm{H} 2$

\subsection{Combined acceleration spectrum}

The Peak Ground Accelerations (PGAs) of the Chi-Chi 1999, Fukushima-Hamadori 2011 and Padang 2009 were scaled down to El-Centro 1940. Figure 8 shows the combined acceleration spectra of the four earthquake time-histories. Spectral matching would reduce the peaks and valleys in each earthquake time history. No spectral matching was done because the four-story steel moment frame was not designed for specific site. Therefore peaks and valleys in Figure 8 of each acceleration spectra are very obvious.

Two cases of the peripheral frames along $\mathrm{H} 1$ considered:

1. Case 0 is the four-story frame without dampers $(T=0.8272$ seconds)

2. Case 1 is the four-story frame with dampers ( $T=0.4918$ seconds)

It is well understood that each point in a response spectra represents the energy content of the earthquake at a certain frequency. For the frame without damper along H1 subjected to Padang earthquake accelerograms, the corresponding point for $T=0.8271$ seconds lies in a valley. Therefore significant response reduction is not expected for Padang earthquake. Significant response reductions are expected for three other earthquakes.

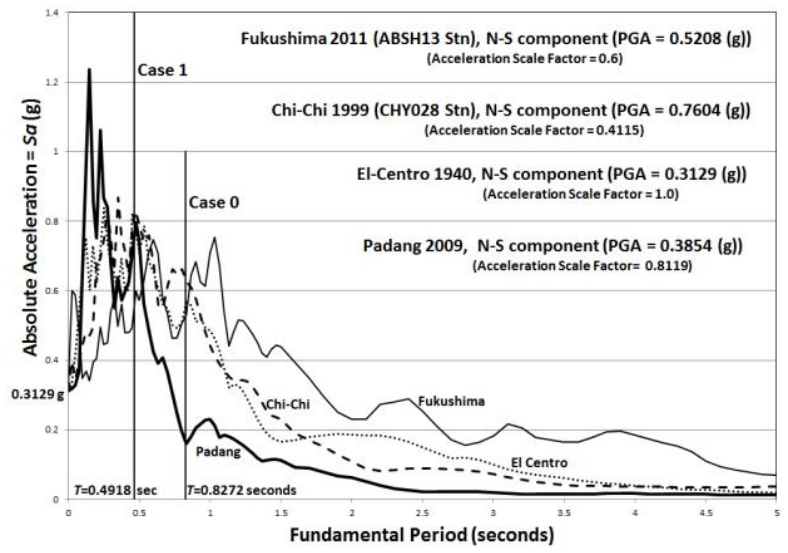

Fig. 8. Combined acceleration spectra

\subsection{Inter-story drift reduction}

The results of nonlinear dynamic analysis of Case 0 and Case 1 were used to quantify the lateral displacement (drift) and inter-story drift ratio of the four-story steel moment frame. The drift and inter-story drift for Case 0 and Caser 1 are shown in Figure 9 and Figure 10 respectively. 


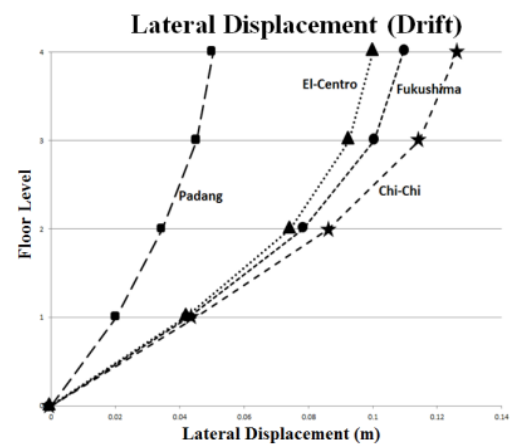

(a)

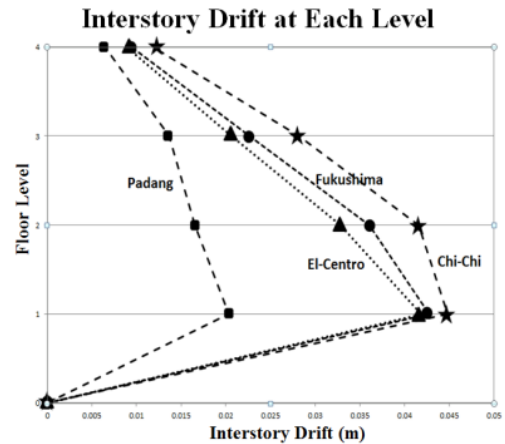

(b)

Fig. 9. Drift and inter-story drift for Case 0: (a) Drift, and (b) Inter-story drift

Figure 9a shows the maximum drift at each floor of the four-story frame without damper. The maximum drift due to Padang 2009 earthquake is small as expected (see Figure 8 ). Figure $9 \mathrm{~b}$ shows the maximum inter-story drift at each floor of the four-story frame without damper.

Figure 10a shows the maximum drift at each floor of the four-story frame equipped with dampers. Figure $10 \mathrm{~b}$ shows the maximum inter-story drift at each floor of the four-story frame with dampers installed. Comparing Figure 9 and Figure 10, it can be seen that the lateral displacement and the inter-story drift were reduced significantly due to the present of dampers in the four-story steel moment frame.

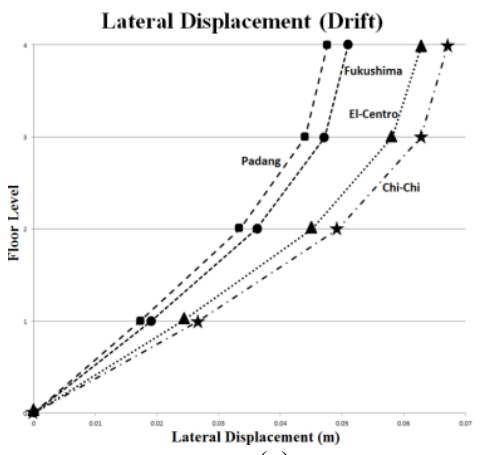

(a)

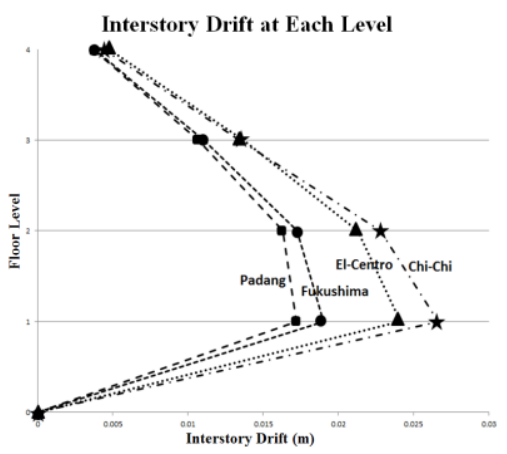

(b)

Fig. 10. Drift and inter-story drift for Case 1: (a) Drift, and (b) Inter-story drift

The reduction of inter-story drift at each floor due to the dampers is shown in Figure 11.

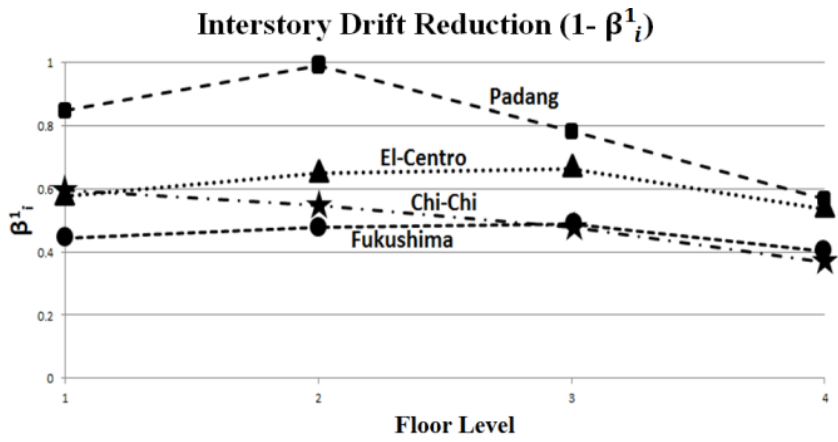

Fig. 11. Inter-story drift reduction 
Parameter $\beta^{1}{ }_{i}$ [7] is used to quantify the ratio of maximum drift at each floor for the frame with dampers to the frame without dampers. The inter-story drift reduction is quantified as $1-\beta_{i}^{1}$. Except for Padang 2009 earthquake where the inter-story drift reduction is expected to be small, the inter-story drift reduction at each floor due to the other earthquakes is significant. On average the inter-story drift reduction at each floor is about $40 \%$.

\subsection{Dissipated inelastic strain energy}

Dissipated strain energy quantified at each component of the four-story steel moment frame in nonlinear dynamic analysis is shown in Table 3.

Table 3. Dissipated strain energy at each component of the peripheral frames along H1

\begin{tabular}{|c|c|c|c|c|}
\cline { 2 - 5 } \multicolumn{1}{c|}{} & \multicolumn{4}{c|}{ Earthquake } \\
\hline Group name & $\begin{array}{c}\text { El-Centro - } \\
\mathbf{1 9 4 0}\end{array}$ & $\begin{array}{c}\text { Fukushima - } \\
\mathbf{2 0 1 1}\end{array}$ & $\begin{array}{c}\text { Padang - } \\
\mathbf{2 0 0 9}\end{array}$ & $\begin{array}{c}\text { Chi-Chi - } \\
\mathbf{1 9 9 9}\end{array}$ \\
\hline Perimeter Columns & 0 & 0 & 0 & 0 \\
\hline Perimeter Beams & 0 & 0 & 0 & 0 \\
\hline Interior Columns & 0 & 0 & 0 & 0 \\
\hline Interior Beams & 0 & 0 & 0 & 0 \\
\hline Connection Panel Zones - along H1 & 0 & 0 & 0 & 0 \\
\hline Connection Panel Zones - along H2 & 0 & 0 & 0 & 0 \\
\hline Vertical Steel Pipe Dampers & $\mathbf{2 6 1 . 4 9}$ & $\mathbf{4 2 2 . 4}$ & $\mathbf{2 0 2 . 3 5}$ & $\mathbf{2 3 3 . 2 9}$ \\
\hline Bracing HSS-H1-1st floor & 0 & 0 & 0 & 0 \\
\hline Bracing HSS-H2-1st floor & 0 & 0 & 0 & 0 \\
\hline Bracing HSS-H2-other floors & 0 & 0 & 0 & 0 \\
\hline Bracing HSS-H1 other floors & 0 & 0 & 0 & 0 \\
\hline Total for All Groups & $\mathbf{2 6 1 . 4 9}$ & $\mathbf{4 2 2 . 4}$ & $\mathbf{2 0 2 . 3 5}$ & $\mathbf{2 3 3 . 2 9}$ \\
\hline
\end{tabular}

Only the vertical steel pipe dampers dissipate energy. All other components except the dampers remain elastic. The present of the dampers installed at strategic locations in the four-story steel moment frame were able to protect the structure against strong earthquakes. Extensive yielding in dampers is the energy dissipation mechanism. By dissipating strain energy, the dampers control the vibration of the structure during strong earthquakes.

The strain energy dissipated by individual damper is shown in Table 4 . The largest value of strain energy dissipated by individual damper located between the $2^{\text {nd }}$ and $3^{\text {rd }}$ floor is due to Fukushima-Hamadori 2011 earthquake. The values of dissipated strain energy of individual damper reflect the damage (the degree of yielding) experienced by the dampers.

Table 4. Dissipated strain energy of individual damper along H1

\begin{tabular}{|c|c|c|c|c|}
\hline \multirow{2}{*}{ Earthquake } & \multicolumn{4}{|c|}{ Dissipated Energy of Individual Damper (kN.m) } \\
\hline & $\begin{array}{c}\text { Damper btw } \\
1^{\text {st }} \text { and } 2^{\text {nd }} \text { floor }\end{array}$ & $\begin{array}{c}\text { Damper btw } \\
2^{\text {nd }} \text { and } 3^{\text {rd }} \text { floor }\end{array}$ & $\begin{array}{c}\text { Damper btw } \\
3^{\text {rd }} \text { and } 4^{\text {th }} \text { floor }\end{array}$ & $\begin{array}{c}\text { Damper btw } \\
4^{\text {th }} \text { floor and roof }\end{array}$ \\
\hline El-Centro & 36.40 & 46.30 & 11.65 & 0.0 \\
\hline Fukushima & 59.32 & 76.71 & 15.86 & 0.0 \\
\hline Padang & 26.37 & 35.18 & 13.26 & 0.0 \\
\hline Chi-Chi & 34.85 & 37.38 & 9.58 & 0.0 \\
\hline
\end{tabular}




\subsection{Maximum absolute shear force and shear displacement}

The maximum absolute value of the shear force and the maximum absolute value of the shear displacement shown in Table 5. The maximum absolute shear force is $513.21 \mathrm{kN}$ which is less than the shear-force capacity of the vertical steel pipe damper. The maximum absolute shear displacement is $18.5 \mathrm{~mm}$ which is very close the $10 \mathrm{x} \delta_{y}$ of the damper $\left(\delta_{y}\right.$ of the damper is $1.80 \mathrm{~mm}$ ). Therefore the performance objectives of the structure had been achieved.

Table 5. Maximum absolute shear force and lateral displacement

\begin{tabular}{|l|c|c|c|c|}
\hline \multirow{2}{*}{ Earthquake } & \multicolumn{2}{|c|}{\begin{tabular}{c} 
Maximum Absolute Shear Force (kN) \\
\cline { 2 - 5 }
\end{tabular}} & $\begin{array}{c}\text { Damper btw 1 } \\
\text { and 2 }\end{array}$ & \multicolumn{2}{|c|}{$\begin{array}{c}\text { Maximum Absolute Shear } \\
\text { Dloor }\end{array}$} & $\begin{array}{c}\text { Damper btw 2 } \\
\text { and 3 }^{\text {nd }} \text { floor }^{\text {and }}\end{array}$ & $\begin{array}{c}\text { Damper btw 1 } \\
\text { and 2 }^{\text {rd }} \text { floor }^{\text {and }}\end{array}$ & $\begin{array}{c}\text { Damper btw 2 } \\
\text { and 3 }^{\text {rd }} \text { floor }^{\text {and }}\end{array}$ \\
\hline El-Centro & 502.63 & 501.88 & 0.0162 & 0.0161 \\
\hline Fukushima & 480.78 & 484.38 & 0.0115 & 0.0122 \\
\hline Padang & 470.01 & 480.17 & 0.0099 & 0.0113 \\
\hline Chi-Chi & $\mathbf{5 1 3 . 2 1}$ & 508.34 & $\mathbf{0 . 0 1 8 5}$ & 0.0175 \\
\hline
\end{tabular}

\section{Conclusion}

The newly developed vertical steel pipe damper was successfully apllied to reduce the seismic response of the moment frame due to four strong earthquakes. The energy dissipation were concentrated in the dampers so that other components of the structure, except the dampers, remain elastic. The performance of the four-story steel moment frame with slender columns at the first floor has been improved significantly by installing dampers at strategic locations. After strong earthquakes, dampers that already experience yielding can be replaced easily.

This research was supported by the Decentralization Research Grant (FTSL PN-1-08-2014 and FTSL PN-1-08-2015) of Directorate General of Higher Education (DIKTI), Ministry of National Education, Indonesia.

\section{References}

1. J. Utomo, Development of Steel Pipe Dampers for Seismic Protection of Buildings, (In Indonesian), Doctoral Dissertation, Institut Teknologi Bandung, Indonesia (2017).

2. D. Y. Abebe, J. W. Kim, and J. H. Choi, Hysteresis Characteristics of Circular Pipe Steel Damper Using LYP225, Steel Innovations Conference 2013, Christchuch, New Zealand, 21-22 February (2013).

3. ABAQUS user's manual, version 6.11, Dassault Systems Corp., Providence, RI, USA (2011).

4. G. H. Powel, User Guide Perform-3D Version 5 - Nonlinear Analysis and Performance Assessment for 3D Structures, Computer and Structures Inc., California (2011).

5. A. Benavent-Climent, Soil Dynamics and Earthquake Engineering, 31: 1385-1396 (2011).

6. A. Benavent-Climent, L. G. Pujades and F. Lopez-Almanza, Earthquake Engng Struct. Dyn.; 31:1151-1172 (2002).

7. C. Tovar, and O. A. Lopez, Effect of The Position and Number of Dampers on The Seismic Response of Frame Structures, $13^{\text {th }}$ World Conference of Earthquake Engineering, Vancouver, B.C., Canada (2004). 